MURRAY, S. O.-Lancet, Vol. I. p. 328, 1947.

Nellen, M.-Lancet, Vol. I, p. 326, 1947.

Nicolau, MmE.-Soc. roum. d'Opht., Bucarest, Vol. XVII. p. 6. 1931; Ref. Ann. d'Ocul., Vol. CLXX, p. 351. 1933.

NoвL.-Wiener Dermat. Ges., Vol. XIII, p. 2, 1895. Quoted by Chaillous.

O Donovan, W. J. and Michálson, L. C.-Brit.Jl. Ophthal., Vol. XXX, p. 193, 1946.

Percival, G. H. and Gibson, H. I.-Brit. Jl. Dermat, Vol. XCIII, p. 329, 1931.

Raffin, A.-Klin. Monatsbl.f. Augenheilk., Vol. LXVIII, p. 216, 1922.

RAMEL, E.-4 ème congr. derm. et syph. de langue franç. Paris, Juillet, 1929. Masson.

RENDU, R. (a).-Kev. gen chir. et de therap., Vol. XXX, p. 351.1916.

(b)-Arch. internat.laryngol. Vol. ViI, p. 482, 1928.

RICHARDS, J. M.-Arch. of Ophthal., Vol. XXXV, p. 380. 1946.

Richards, J. M. and Rumaine, H. H.-Amer. Ji. Ophthal., Vol. XXIX, p. r121, 1946.

RIGLER-Die Türkei und ihre Bewohner, Wien, 1852, Vol. II, p. 45. Quoted by Steffens and Edmund.

Rosenberg, L. and Rosenberg, J.-Arch. of Dermat., Vol. XLI, p. 1066, 1940.

SalUS. R.-Klin. Monatsbl. f. Augenheilk., Vol. L, pp. 1, 30, 1912.

SNEDDON, J. B.-Lancet, Vol. I, p. 466, 1947.

Speckman, H. M.-Niederl. Ophthal. Ges., 24/25-5-1941; Ref. Zentralbl. f. Ophthal., Vol. XLVIII, p. 10, 1942.

Stainsby, W. J.-Erythema multiforme. Cecil Text-book Medicine, 5th Ed., 1942, Saunders.

Steffens.-Klin. Monatsbl. $f$. Augenheilk., Vol. XL, II, p. 50, 1902.

Stevens, A. M. and Johnson, F. C.-Amer. Jl. Dis. Child., Vol. XXIV, p. 526, 1922.

STORCK, H.-Schw. med. Wschr., p. 1102, 1942.

TERSON, A.-Troubles oculaires dans l'erythème polymorphe. Assoc. pour l'avancement des sciences. Congr. Bordeaux, 1895. Quoted by Terson, 1912. Arch. d'Ophthal., Vol. XXXII, p 274, 1912.

URNiker, W. and Crofoot, M.-U.S. Naval Med. Bull., Vol, XLVI, p. 1466, 1946.

WheEler, J. M.-Amer. Jl. Ophthal., Vol. XIII, p. 508, 1930.

\title{
CONICAL CONTACT LENSES
}

BY

\section{G. D. MCKELLEN}

CoNic̀al contact lenses-i.e., contact lenses having haptics in the form of a truncated cone-were designed and first produced by Dr. William Feinbloom, of New York, who described them in an article in the " Optometric Weekly", in 1945. Dr. Feinbloom stated in that article that the major problem in contact lens fitting has always been that of reducing to a minimum the pressure of the lens on the eye. He was using Zeiss ground lenses "with spherical haptics prior to 1930 , and read a paper dealing exhaustively with this type of lens at the American Academy of Optometry meeting in Omaha in 1930. After ten years' experience with this type, he changed over to the moulding method, which he described in a paper at the Academy meeting at Chicago in 1936. 
After carrying out this technique on some thousands of eyes, he decided that it was easier to carry out the necessary grinding and adjusting on standard lenses of a shape more truly representing the shape of the eye than spherical lenses. Study of the moulds taken, showed that the curves of the surface of the eye are toroidal rather than regularly spherical, and he developed a series of lenses with toroidal haptics in 1940 . He says that "While these lenses gave results that were a significant advance on those given by the older types, he was still dissatisfied." He then stated the problem thus-"What form should the haptic of a contact lens take in order to produce minimum pressure on the sclera and conjunctiva?" And "At what places should the lens rest on the sclera so that the pressure remains minimal, even when the lens moves?" A long series of experiments was undertaken to determine the effects of changes of surface forms, and the main conclusions arrived at were :-

(1) the surface used must rest on an area,sufficiently behind the limbus to avoid pressure there;

(2) this surface must be sufficiently inside the edge of the lens to prevent the edge from digging when worn for a long period of time ;

(3) this surface must rest on an area narrow enough to allow change to a new area as the eye moves;

(4) if the lens rests on the prescribed areas, then the more tangential the surface of the haptic is to the eyeball, the less the pressure on the eye.

Thus the "conical" haptic was arrived at, and " Feincone" lenses were introduced. A " Feincone" lens is made up of three parts-the spherical " optic," the conical " haptic," and a temporal flange. The purpose of the flange is to carry the temporal edge into the outer fornix and bring it into bare contact with the bulbar conjunctiva, so that it does not rub the lid margins at the outer canthus where the lid pressure is greatest. A noticeable feature of the conical lens is the almost complete absence of the transition shoulder or ridge that can be felt in other types. This, I think, is an important point to which I will refer later.

There are five variables in the conical lens:-

The angle of the cone.

The radius of curvature of the flange.

The overall size.

The radius of curvature of the optic.

The diameter of the optic.

The cone angle determines the position of the area of contact of the haptic for a given eye. The smaller the angle of the cone, 
the further back the area of contact. Compare Fig. 1 with Figs. 5 and 6.

In the Feincone series the angles are $80 \mathrm{deg} ., 86 \mathrm{deg} ., 92 \mathrm{deg}$., $98 \mathrm{deg} ., 104 \mathrm{deg}$. and $110 \mathrm{deg}$., though they are specified by the half-angle-40 deg., $43 \mathrm{deg.,} 46 \mathrm{deg}$., $49 \mathrm{deg}$., etc. The most commonly used angles are $43 \mathrm{deg}$. and $46 \mathrm{deg}$.

The flange radii are $12 \mathrm{~mm} ., 12.6 \mathrm{~mm} ., 13.2 \mathrm{~mm}$. and $13.8 \mathrm{~mm}$.

The " standard" overall size is about $23 \mathrm{~mm}$., but smaller and larger lenses can be obtained, specified + or $-1,2,3,4$, or 5 .

The radius of curvature of the inner surface of the optic is normally $8.5 \mathrm{~mm}$. in the $40 \mathrm{deg} ., 43 \mathrm{deg}$. and $46 \mathrm{deg}$. angles, and

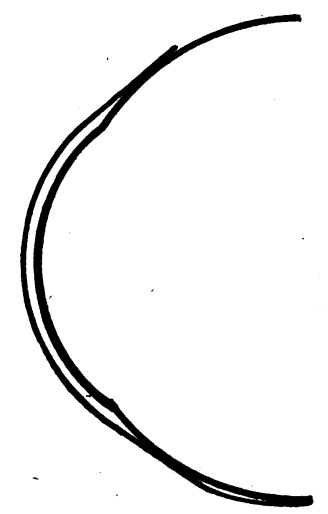

FIG. 1.

A well-fitting conical lens.

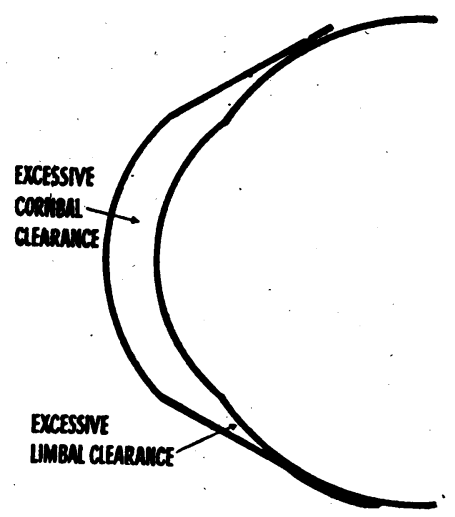

FIG. 2.

Lens of too small an angle of cone. 
$8 \mathrm{~mm}$. in the $49 \mathrm{deg}$. , but any radius from $7,7.5,8$, to $8.5 \mathrm{~mm}$. is obtainable with any angle.

The normal diameter of the optic is $12 \mathrm{~mm}$., but the whole series can be obtained with $14 \mathrm{~mm}$. diameters if required. This is an advantage in certain cases-those having unusually large corneae.

There are also double-angle lenses which are useful for large flat eyes (Fig. 3).

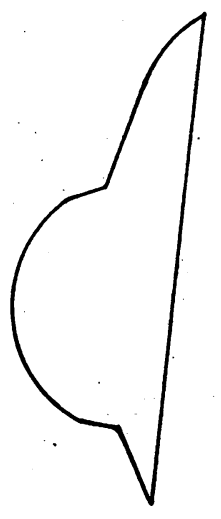

Showing tight flange. Note how lens is lifted so that haptic does not rest on sclera.

Double-angle haptic.

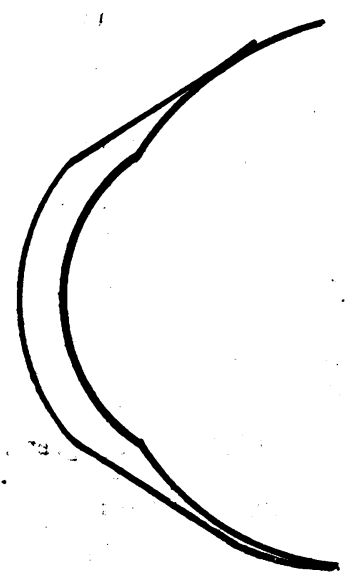

Fig. 4.

FIG. 3. 
The fluorescein test is used to determine the correct angle of cone and radius of curvature of the optic. The aim is to put the band of contact two or three millimetres behind the limbus and to give positive corneal clearance with the eye in the primary position (see Figs. 1 and 5).

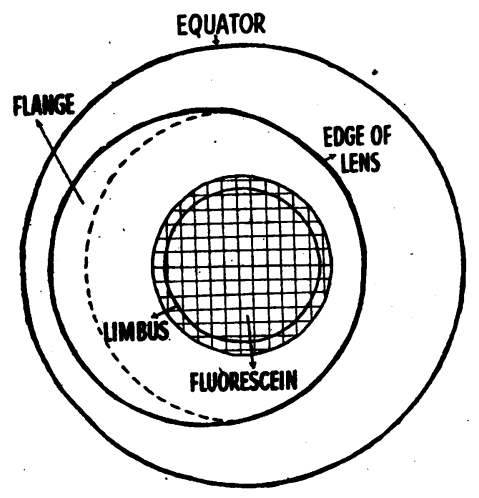

FIG. 5 .

Lens on eye, frontal view. Showing minimum limbal clearance.

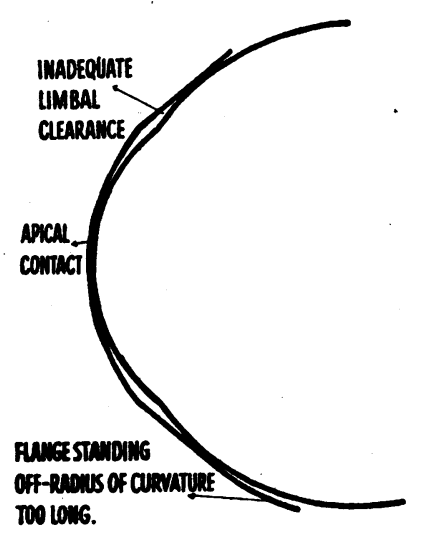

FIG. 6.

Angle of cone too great.

The limbal clearance must not be too great, or the lens tends to edge contact and lags badly, and protrudes too far, giving a poor cosmetic effect (Fig. 2). The lens should be allowed to remain in situ for half an hour before final judgment as to the correctness of the selected cone angle is pronounced. In some cases the lenses settle back quite a lot-owing probably to the thickness, looseness and texture of the conjunctiva and episcleral tissue. 
While selecting the cone angle it is necessary to watch the flange also. If the flange is too steep so that it digs, the whole lens may be lifted so that the cone does not make contact in the normal manner, even though it is of the correct angle (Fig. 4). The fluorescein will then extend right'to the periphery. The flange should make bare contact with the conjunctiva.

When the correct angle of cone, radius of flange and radius of curvature of the optic have been chosen, any sensation the patient reports will be due to the rubbing of the lids against the edges of the lens. This may well be due to wrong over-all size, and the same lens of smaller or larger diameter should be tried. In some cases-usually cases of rather marked irregularity of the surface of the globe-there may be a loose edge at one localised part. necessitating either grinding off or bending with the "Feincone" forceps-a forceps with parallel jaws curved to approximately the curves of the haptic, which is heated in boiling water and applied to the area to be bent. In the hands of an experienced operator these forceps are of very great value, eliminating the need for much grinding, etc. Feinbloom's own instructions regarding examination of the edge fit are :-

Examine the edges in ordinary light in this order :-

(a) Superior-if tight (blood'vessels interrupted and conjunctiva blanched) angle of cone is too small. If loose but no loss of liquid occurs, ignore.

(b) Superior-nasal-this must not be tight or it will certainly cause trouble. If tight, increase angle. If loose, without loss of liquid, ignore.

(c) Nasally (at 180 deg.)-should be loose without loss of fluid. If tight, increase angle of cone.

(d) Temporally - flange edge must just rest against conjunctiva. If tight, increase radius of curvature of flange. If standing off. decrease radius of curvature of flange.

A good method of showing that the sensations described by the patient are due to lid irritation is to lift the lid away from the lens at the point indicated by the patient as being "tight " or otherwise uncomfortable. If the sensation disappears as the lid is lifted away, it is almost certainly pure " lid-sensation," due to rubbing of the palpebral conjunctiva against the edge of the lens. The edge of the lens may need adjustment, or the sensation may pass away after a few minutes. A patient with tight lids will feel the edges of the lenses more than one with loose lids, and due allowance must be made for this factor. Repeated insertion and removal of the lenses is the best remedy for tight lids.

A well-fitted conical lens should be worn for four hours at the first attempt, without any discomfort.

Conical lenses are now being made in England. The only 
English-made ones of which I have experience are the " Kelvin " lenses made in Manchester. They are based on the same principles as the "Feincone" lenses, but are made of a harder plastic, and are thinner. The flange is not spherical in curvature-its curve is, I believe, hyperbolic in form-and this has reduced the " hump" at the temporal side. The flange curves smoothly from the haptic and follows the curve of the sclera closely. The "Kelvin" series provides a rather larger range of cone angles, 84 deg., 88 deg., 92 deg. (the same as the "Feincone" 46 deg.) $96 \mathrm{deg} ., 100 \mathrm{deg} ., 104 \mathrm{deg} .-i . e$. in steps of $4 \mathrm{deg}$. instead of $6 \mathrm{deg}$. Each cone angle can be obtained with radius of curvature of optic of $7 \mathrm{~mm}$., $7.5 \mathrm{~mm}$., $8 \mathrm{~mm}$. or $8.5 \mathrm{~mm}$, as required. The flange curvatures vary from $12.25 \mathrm{~mm}$. to $14.5 \mathrm{~mm}$. radius. The optic is decentred bodily towards the nasal edge, the standard decentration being $12 \frac{1}{2}$ deg., which can be varied to $14.5 \mathrm{deg}$. or $10.5 \mathrm{deg}$. The $10.5 \mathrm{deg}$. decentration gives more material nasally and less temporally : the $14 \cdot 5 \mathrm{deg}$. gives less nasally and more temporally.

"Double-angle" lenses are available in 'The " Kelvin" series. These have two different angles of cone in meridians at right angles to each other. The meridians can be at any position-say $180 \mathrm{deg}$. and $90 \mathrm{deg} ., 45 \mathrm{deg}$. and $135 \mathrm{deg}$., $60 \mathrm{deg}$. and $150 \mathrm{deg}$., etc. The effect is a "squashed" cone which will fit a " toric " sclera. A regular cone will fit a toric sclera if the toricity is not too great. The fluorescein pool will be oval, with the long axis of the oval along the meridian of steepest curvature, in such a case, but this does not matter so long as the band of contact does not reach the edge of the lens. In some of these cases it is necessary to fit an oval lens, e.g., instead of $23.5 \mathrm{~mm}$. diameter, $24.5 \times 235 \mathrm{~mm}$., long axis vertical. This would be sufficient to take care of a mild toricity. If the eye cannot be fitted satisfactorily this way, a double-angle lens-say LF (96 deg. and $92 \mathrm{deg}$.) should be tried, and if this difference is still not enough, the LE (96 deg. and 88 deg.) should be tried, and so on. These double-angle lenses are most useful, and differences up to $16 \mathrm{deg}$. are provided. Any scleral toricity of such degree that the double-angle lenses with 16 deg. difference will not cope with it, indicates the need for moulding. The double-angle series will cope with scleral toricity far beyond the range of oval ground sphericals.

My own experience with conica! lenses has satisfied me that there is a definite place for this type in the armoury of every serious practitioner. The fitting technique is a good deal simpler than any other and takes much less time, which is an advantage from the patient's point of view, at least. I believe that 50 per cent. of the would-be wearers of contact lenses can be fitted with conical lenses with results at least as good as those of any other method- 
in some cases with better results, because some eyes are of a shape that is ideal for the conical lens and less suited to any other type. If 50 per cent. of one's patients can be satisfactorily fitted by a method that takes half the time required for any other, it would be stupid not to use it. I am not advocating hurried work, but I do feel that any technique that shortens the time required for satisfactory fitting is to be encouraged.

It is also true that there are some eyes that cannot be fitted satisfactorily with conical lenses or can better be fitted with other types. No attempt should be made to fit these cases with conical lenses, and if necessary, they should be referred' to other practitioners who are masters of the more difficult techniques of fitting moulded and ground spherical lenses.

There is no doubt that, for a recruit to contact lens fitting, the conical type is the easiest and least expensive to begin with, and will cover a wider range of patients satisfactorily, than will any other type. Nevertheless, the aim of all practitioners should be to fit all types. Fitting conical lenses will enable the beginner to gain confidence and experience for the more difficult work.

Conical lenses are extremely comfortable to wear, it is relatively easy to obtain a perfectly comfortable fit. This is due in part, I think, to the absence of the transition ridge, and partly to the fact that the lens rests well behind the limbus on a narrow band of conjunctiva, and changes its position of contact slightly as the eye moves. The veiling problem does not seem to be eased appreciably by the use of conical lenses. One gets the same widely varying results as with other types. Conical lenses lend themselves to experiments along the lines of fenestration, grooving of the haptic, etc., as well as any other type, but no considerable work has been done in this direction so far.

The last word on contact lens design has not yet been said, but the use of conical lenses will no doubt lead to some further developments. I would say, from my own experience, that the advent of conical lenses has advanced the science of contact lens fitting, and provided us with a simple and less time-consuming method of obtaining a comfortable and satisfactory fit for a large percentage of our patients. It has shown that the "glove fit" is not necessarily the correct ideal to strive for, and that a design far removed from the moulded lens may yet prove to be the answer to some of the problems with which we are faced. 